\title{
Knock-Down of Heat-Shock Protein 90 and Isocitrate Lyase Gene Expression Reduced Root-Knot Nematode Reproduction
}

\author{
Isabela Tristan Lourenço-Tessutti, José Dijair Antonino Souza Junior, Diogo Martins-de-Sa, Antônio Américo Barbosa \\ Viana, Regina Maria Dechechi Gomes Carneiro, Roberto Coiti Togawa, Janice de Almeida-Engler, João Aguiar Nogueira \\ Batista, Maria Cristina Mattar Silva, Rodrigo Rocha Fragoso, and Maria Fatima Grossi-de-Sa
}

First, second, third, fourth, fifth, sixth, eighth, ninth, and eleventh authors: Embrapa Genetic Resources and Biotechnology, Laboratory of Molecular Plant-Pest Interaction, Brasília, DF, Brazil; first, second, and third authors: University of Brasília, Department of Cell Biology, Graduate Program in Molecular Biology, Brasília, DF, Brazil; seventh author: Institut National de la Recherche Agronomique, SophiaAntipolis, France; eighth author: Federal University of Minas Gerais, Botany Department, Belo Horizonte, MG, Brazil; tenth author: Embrapa Cerrados, Laboratory of Phytopathology, Planaltina, DF, Brazil; and eleventh author: Catholic University of Brasília, Graduate Program in Genomic Sciences and Biotechnology, Brasília, DF, Brazil.

Accepted for publication 29 December 2014

\begin{abstract}
Lourenço-Tessutti, I. T., Souza-Junior, J. D. A., Martins-de-Sa, D., Viana, A. A. B., Carneiro, R. M. D. G., Togawa, R. C., de Almeida-Engler, J., Batista, J. A. N., Silva, M. C. M., Fragoso, R. R., and Grossi-de-Sa, M. F. 2015. Knock-down of heat-shock protein 90 and isocitrate lyase gene expression reduced root-knot nematode reproduction. Phytopathology 105:628-637.

Crop losses caused by nematode infections are estimated to be valued at USD 157 billion per year. Meloidogyne incognita, a root-knot nematode ( RKN), is considered to be one of the most important plant pathogens due to its worldwide distribution and the austere damage it can cause to a large variety of agronomically important crops. RNA interference (RNAi), a gene silencing process, has proven to be a valuable biotechnology alternative method for RKN control. In this study, the RNAi approach was applied, using fragments of $M$. incognita genes that encode for two essential molecules,

heat-shock protein 90 (HSP90) and isocitrate lyase (ICL). Plant-mediated RNAi of these genes led to a significant level of resistance against M. incognita in the transgenic Nicotiana tabacum plants. Bioassays of plants expressing $H S P 90$ dsRNA demonstrated a delay in gall formation and up to $46 \%$ reduction in eggs compared with wild-type plants. A reduction in the level of $H S P 90$ transcripts was observed in recovered eggs from plants expressing dsRNA, indicating that gene silencing persisted and was passed along to first progeny. The $I C L$ knock-down had no clear effect on gall formation but resulted in up to $77 \%$ reduction in egg oviposition compared with wild-type plants. Our data suggest that both genes may be involved in RKN development and reproduction. Thus, in this paper, we describe essential candidate genes that could be applied to generate genetically modified crops, using the RNAi strategy to control RKN parasitism.
\end{abstract}

Plant nematode parasitism is one of the most important biotic stresses of several economically important crops (51). On a worldwide basis, the annual cost of crop losses due to phytonematode damage is estimated to reach more than 157 billion U.S. dollars per year (1). The root-knot nematode (RKN) Meloidogyne incognita is considered one of the most harmful plant pathogens due to its global distribution and the serious damage it causes to a large variety of plant crops. This plant nematode has a life cycle divided in six developmental stages (eggs, juvenile stage 1 to 4 , and adult), that lasts near 28 days (1), which ends in apomictic females laying down nearly 2,000 eggs (87). Eggs develop to J1 through embryogenesis, which remain inside eggshell. After the first ecdysis, $\mathrm{J} 1$ become $\mathrm{J} 2$, which in turn eclode from eggshell to find a plant host. The preparasitic juveniles (ppJ2) are microscopic worms of 200 to $400 \mu \mathrm{m}$ in length that penetrate the root elongation zone, migrate intercellularly to the root tip, and then enter the vascular cylinder where the feeding site is established (88). To feed and complete their life cycle, these parasites choose five to seven living cells present in root vascular tissue, inject their secretions that will change plant cells to giant feeding cells, which provide nutrients for nematode development (70). Many physiological

Corresponding author: M. F. Grossi-de-Sa; E-mail address: fatima.grossi@embrapa.br R. R. Fragoso and M. F. Grossi-de-Sa are co-last authors.

*The $\boldsymbol{e}$-Xtra logo stands for "electronic extra" and indicates that nine supplementary figures and three supplementary tables are published online.

http://dx.doi.org/10.1094/PHYTO-09-14-0237-R

(C) 2015 The American Phytopathological Society and morphological changes occur during the formation of giant cells. These feeding cells become hypertrophied and multinucleated as a result of various mitotic cycles without cytokinesis (22); hyperplasia is also observed in cells neighboring the giant cells.

Currently, there are four primary strategies for phytonematode control, as follows: chemical treatment with nematicides, biological control, crop rotation, and quarantine when the area is not infected with nematodes (13). However, integrated pest management is efficient to control plant nematode just in some cases. Genetic resistance is the most effective way to circumvent $\mathrm{RKN}$, but natural resistance genes are only known in some crops. Therefore, a promising approach is the application of genetic engineering to generate crop plants with high levels of nematode resistance (59).

RNA interference (RNAi) is a Eukarya ubiquitous physiological mechanism of gene expression regulation, which reduces transcription or translation rates of a specific gene, mediated by doublestranded RNA (dsRNA). Such mechanism became a major technique widely used for functional genomics studies (44). The first RNAi studies in plant-parasitic nematodes were performed using dsRNA soaking with eggs or $\mathrm{ppJ} 2$ to knock-down specific genes. This method showed different levels of gene knock-down efficiency, duration, and phenotype. The effectiveness of soaking method seems to depend on dsRNA size, concentration, incubation time, target gene and its expression pattern, and nematode species $(5,9,10,16,30,40,46,52,79)$. In most cases, target gene expression increased within days after soaking, which is a problem to evaluate genes expressed in adult female. The limitations of the soaking method prompted the development of dsRNA expression in planta that reportedly is a successful 
technique for knocking down the expression of nematode genes. Using in planta RNAi, almost complete resistance was observed by Huang et al. (40), which knocked-down the $16 D 10 \mathrm{M}$. incognita parasitism gene in Arabidopsis thaliana, leading to a significant reduction of gall formation. Most recently, a $16 D 10$ ortholog, Mc16D10L, was identified in $M$. chitwoodi and host-delivered RNAi increased resistance in A. thaliana and potato plants. In transgenic A. thaliana, the number of egg masses and eggs were reduced by up to 57 and $67 \%$ compared with empty vector controls, respectively (28). In stable transgenic lines of potato, the number of egg masses and eggs were reduced up to 71 and $63 \%$, respectively, compared with empty vector controls (27). Another study showed a high level of resistance in Vitis vinifera to $M$. incognita when the $16 D 10$ gene was silenced (93). Besides, silencing the parasitism gene $8 D 05$ of $M$. incognita showed up to $90 \%$ resistance in A. thaliana (91). Then, tobacco plants expressing dsRNA for other two genes, splicing factor and integrase, showed a huge decrease in number of galls and egg masses (92). Silencing two FMRF amide-like genes, flp-14 and flp-18, resulted in a 50 to $80 \%$ reduction of $M$. incognita infection and multiplication in tobacco plants (64). Furthermore, silencing aspartic, cysteine, and serine proteases in M. incognita had a negative effect on nematode vigor. A $35 \%$ mean reduction in the number of eggs per gram of roots and a $40 \%$ decrease in the hatching rate of eggs collected from tobacco plants expressing dsRNA targeting for serine protease were reported (7).

The host-delivered dsRNA gene targeting method has also been used to knock-down the expression of cyst nematode genes. Knockingdown a Heterodera glycines major sperm protein gene led to a $75 \%$ reduction in egg production in soybean transgenic roots (84). In other study, A. thaliana plants were transformed with hairpin constructs targeting $H$. schachtii splicing factor $H s-U 2 A F$, vacuolar $H s-H^{+}$ ATPase or ubiquitin extension protein $\mathrm{Hs}$ - Ubi, and infection experiments showed up to $50 \%$ reduction for some transgenic lines (48). The expression of three $H$. glycines reproduction or fitness genes, Cpn-1, Y25, and Prp-17, resulted respectively in 95, 81, and $79 \%$ reduction in eggs per gram of roots $(50)$. Furthermore, silencing a gene that encodes for an aldolase from $\mathrm{H}$. glycines reduced in $58 \%$ the number of mature females in transgenic soybean roots (94).

In this study, we down-regulated the expression of two stresstolerance and survival-related genes, heat-shock protein 90 (HSP90) and isocitrate lyase (ICL), of M. incognita by dsRNA expression in planta. Agrobacterium tumefaciens was used to transform Nicotiana tabacum plants with RNAi vectors for the expression of $H S P 90$ and $I C L$ dsRNA. Genetic modified plants in which either target gene was silenced were challenged with $M$. incognita to determine the level of nematode infectivity. Knocking-down either $H S P 90$ or the ICL gene strongly affected $M$. incognita reproduction, suggesting the functional application of this gene knock-down strategy for nematode resistance.

\section{MATERIALS AND METHODS}

Nematode culture. The plant-parasitic nematode $M$. incognita race 3 was propagated and maintained in tomato (Solanum lycopersicum L.) plants 'Santa Cruz' under greenhouse conditions. Nematodes were harvested at different life stages (egg and $\mathrm{J} 1$ within the eggshell; ppJ2 ecloded; parasitic J2, J3, and J4; and adult female) using standard protocols (41). Tomato roots at 30 days after inoculation (DAI) were washed and ground using a blender for $2 \mathrm{~min}$ in $0.5 \% \mathrm{NaClO}$. The eggs were separated by passing all of the material through a 32- $\mu \mathrm{m}$ sieve. The collected fraction was cleaned by centrifugation in $50 \%$ (wt/vol) sucrose, and the eggs were collected from the supernatant and passed through a $32-\mu \mathrm{m}$ sieve again. Preparasitic J2s were obtained from eggs hatched in vitro. The egg suspension was subjected to a modified Baermann funnel technique and was maintained at room temperature in a recipient containing distilled water to enable egg hatching for subsequent collection of ppJ2. Nematodes of parasitic stages (J2, J3, and J4) were manually collected from roots at 7 to 21 DAI after washing and incubating overnight in $40 \%$ ( $\mathrm{vol} / \mathrm{vol})$ pectinase. Adult parasitic females were obtained from roots at $30 \mathrm{DAI}$ that had been incubated overnight in $40 \%$ ( $\mathrm{vol} / \mathrm{vol}$ ) pectinase to release the females from the digested root. The sample was then cleared via centrifugation in $40 \%$ (wt/vol) sucrose, and the females in the supernatant were collected using a $150-\mu \mathrm{m}$ sieve.

Expressed sequence tag (EST) library construction. Several ppJ 2 collections were done to obtain $6 \mathrm{ml}$ of $M$. incognita using in vitro eclosion system as described above, which were ground using liquid nitrogen to total RNA extraction using $4 \mathrm{ml}$ of TRIzol reagent (Life Technologies, Carlsbad, CA) as described by the manufacturer. At the final step, the RNA pellet was suspended in $100 \mu \mathrm{l}$ of RNase free water, which resulted in $550 \mu \mathrm{g}$ of total RNA. The poly (A+) RNA was then purified from $440 \mu \mathrm{g}$ of total RNA using the Oligotex kit (Qiagen, Valencia, CA) according to the manufacturer's instructions, which led to $8.1 \mu \mathrm{g}$ of mRNA. This sample was used to construct a cDNA library using the SuperScript Plasmid System and the Gateway Technology for cDNA Synthesis and Cloning kit (Life Technologies) according to the manufacturer's instructions. The mRNA was used as a template for the synthesis of the first cDNA strand via a reverse transcription reaction. First, the mRNA was digested using RNase $\mathrm{H}$, and the second cDNA strands were synthesized using DNA polymerase. The resulting dsDNAs were then cloned into a pSPORT vector (Life Technologies). The generated plasmids were used to transform Escherichia coli competent cells. Single colonies were collected, and the plasmidial DNA was extracted and subjected to sequencing.

EST assembly and computer analysis. The 2,880 obtained chromatograms from the Sanger sequencing were processed for base calling and quality control by PHRED program (30). The screening for vector and bacterial sequences was performed using the cross_match program (35) in NCBI UniVec database. The resulting sequences with at least 200 nucleotides and PHRED quality score higher than 20 was clustered by cap3 program (43). The resulting 197 contigs and 1,506 singlets, hereafter denoted as groups totalizing 1,703 sequences, were preannotated using a pipeline that included automatic processing using BLASTx (6). Three databases were used: GenBank nr (all nonredundant GenBank CDS; www.ncbi. nlm.nih.gov), KOG (85), and swiss-prot release 44 (us.expasy.org/ sprot/). BLASTx analysis was performed using the cutoff E-value of 1e-5. Additional analyses were performed by comparing the EST database to Heterodera (NCBI TaxID 34509) and Globodera genera (NCBI TaxID 31242) nucleotide sequences (including EST) and also to the Caenorhabditis elegans CDS. All the sequences were retrieved from the NCBI Tax browser (www.ncbi.nlm.nih.gov/taxonomy/). tBLASTx was used to compare each $M$. incognita group to the abovementioned nematode sequence. The computer analyses were performed on Intel based computers (P4 and Xeon) using the Fedora Linux operating system. The scripts and programs were developed using PERL language and the web pages using JavaScript and html. Blast2GO software (18) was used to analyze results and to make corresponding graphs (Supplementary Figs. 1 to 6). The 2,378 chromatograms were deposited at NCBI EST division of GenBank $\mathrm{dbEST}$ and received the access number LIBEST_028536.

Quantitative real-time polymerase chain reaction (PCR). To quantify the transcript expression levels of both target genes, the total RNA was isolated from eggs, ppJ2, parasitic J2/J3/J4, and adult females using an RNeasy Mini Kit (Qiagen) according to the manufacturer's instructions. The isolated RNA was treated with DNase I to eliminate any genomic DNA contamination. Overall, 1- $\mu \mathrm{g}$ aliquots of total RNA were reverse transcribed using SuperScript III reverse transcription for qPCR (Life Technologies) according to the manufacturer's instructions, and all cDNA aliquots were stored at $-20^{\circ} \mathrm{C}$. Quantitative PCR was performed using the Master Mix SYBR Green Rox Plus (LGC, Brazil) in triplicate reactions for each gene of each developmental stage. The final volume of reaction mixtures was $10 \mu \mathrm{l}$, including $5 \mu \mathrm{l}$ of Master Mix, $2 \mu \mathrm{l}$ of cDNA, $2.6 \mu \mathrm{l}$ of double distilled $\mathrm{H}_{2} \mathrm{O}$, and $0.2 \mu \mathrm{l}$ of each primer at $10 \mu \mathrm{M}$. 
The target genes, HSP9O and ICL, and the reference genes, GAPDH, $\beta$-tubulin, elongation factor, and $18 S$ rRNA, were amplified using genespecific primers (Supplementary Table 1) designed using the Primer Express 1.5 software (Life Technologies). The PCR conditions were as follows: $95^{\circ} \mathrm{C}$ for $15 \mathrm{~min}$, followed by 40 cycles of $95^{\circ} \mathrm{C}$ for $15 \mathrm{~s}$ and $60^{\circ} \mathrm{C}$ for $1 \mathrm{~min}$, followed by a melting curve step (ramp from 60 to $94^{\circ} \mathrm{C}$, reading every $0.5^{\circ} \mathrm{C}$ ) using a 7500 Fast qPCR machine (Life Technologies). The relative expression levels were calculated according to the Pfaffl method (68). Miner software was used to determine the xthreshold cycle and amplification efficiency values (http://www. miner.ewindup.info) (31), and the relative expression levels were obtained using the program qBase Plus (Biogazelle, Belgium) (37).

In situ hybridization. To evaluate the spatial distribution of HSP90 and ICL mRNA, whole mount in situ hybridization was performed. In situ hybridizations were performed essentially as described by de Boer et al. (23). Sense and antisense RNA probes labeled with digoxigenin were generated by in vitro transcription using target genes that had been cloned into the pGEM-T easy vector (Promega, Madison, WI) and a DIG RNA labeling kit (Roche). Freshly hatched ppJ 2 were fixed using $2 \%$ paraformaldehyde for $21 \mathrm{~h}$ at $5^{\circ} \mathrm{C}$ followed by a second incubation for $6 \mathrm{~h}$ at room temperature. The nematodes were randomly cut using a razor blade and were permeabilized using proteinase $\mathrm{K}$, acetone, and methanol. The nematode fragments were then hybridized at $50^{\circ} \mathrm{C}$ with the sense or antisense riboprobe. Following a digestion with RNase A, the labeled transcripts were detected using alkaline-phosphatase immunostaining. The stained $\mathrm{ppJ} 2 \mathrm{~s}$ were examined using differential interference contrast microscopy (AxiocamHRc, Zeiss).

Cloning HSP90 and $I C L$ gene fragments into RNAi vectors. After the selection of $H S P 90$ and $I C L$ as candidate genes for silencing, specific gene regions were chosen using the Block-IT RNAi Designer program (http://rnaidesigner.invitrogen.com) and BLASTn (www.ncbi.nlm.nih.gov). We selected HSP90 (732 bp) and ICL (266 bp) gene fragments, as they showed no similarity with any sequence of the nonredundant GenBank or with any other sequence of the $M$. incognita genome (Supplementary Figs. 7 and 8). The $H S P 90$ gene fragment was amplified from a clone isolated from the $M$. incognita $\mathrm{ppJ} 2$ EST library described above. The $I C L$ gene fragment was directly isolated from $M$. incognita $\mathrm{ppJ} 2 \mathrm{cDNA}$. For cloning purposes, we used the Gateway system (Life Technologies) according to the manufacturer's instructions. The target gene fragments were amplified using ICL-MiFor and ICL-MiRev or HSP90MiFor and HSP90-MiRev primer sets that included attB1 and attB2 recombination sites. The PCR products were purified, subcloned into the pDONR221 vector (Life Technologies) using BP clonase, and subsequently subcloned in the binary vector pK7GWIWG2-I (43) for dsRNA expression in transgenic plants using LR clonase. The expression constructs consisted of the sense and antisense gene fragment separated by an intron and driven by the CaMV35S promoter. The expression cassette also contained the $35 \mathrm{~S}$ terminator and the nptII gene for kanamycin selection, and both constructs were checked by sequencing before being used for plant transformation.

The generation and selection of transgenic RNAi tobacco lines. The plasmid constructs for the plant transformation and expression of the $H S P 90$ and $I C L$ dsRNAs were electroporated into the A. tumefaciens GV3101 strain and plated onto LB medium containing rifampicin $(100 \mu \mathrm{g} / \mathrm{ml})$, kanamycin $(50 \mu \mathrm{g} / \mathrm{ml})$, and streptomycin $(300 \mu \mathrm{g} / \mathrm{ml})$. The transformed A. tumefaciens cells were cocultured with $1 \mathrm{~cm}^{2}$ leaf discs of $N$. tabacum (variety SR1), followed by in vitro tissue culture (39). The leaf discs were grown in MS medium containing kanamycin at $300 \mu \mathrm{g} / \mathrm{ml}$. The genetically modified (GM) tobacco plants (T0) differentiated from leaf cells were then transferred to plant pots containing soil and were acclimatized in a greenhouse. The $\mathrm{T} 0$ seeds were collected and were stored at $4^{\circ} \mathrm{C}$ until use. For the selection of transformed plants, the seeds were surface sterilized by incubation in $70 \%$ ethanol for $5 \mathrm{~min}$, then incubated in $1 \% \mathrm{NaClO}$ for $30 \mathrm{~min}$ and washed four times using sterile water. Then, the seeds were germinated in MS containing kanamycin $(300 \mu \mathrm{g} / \mathrm{ml})$, and the resistant plants were acclimatized in a greenhouse. The DNA samples were extracted from leaves of GM tobacco plants and were evaluated by PCR to confirm plant transformation and kanamycin selection (Supplementary Figs. 7 and 8). For phenotypic evaluation, macroscopic observations were performed at 30 days after seed germination using five GM tobacco independent lines for each target gene, and no phenotypic variation was observed compared with the wild-type tobacco (nontransgenic NT). These observations showed that transgene insertion did not alter the plant morphology.

Nematode challenge bioassays. The seeds were superficially sterilized (as described above), germinated in vitro in MS medium containing kanamycin $(300 \mu \mathrm{g} / \mathrm{ml})$, and maintained for 20 days. The GM tobacco plants were individually transplanted in sterilized soil and were maintained in a growth chamber with $16 \mathrm{~h}$ light $/ 8 \mathrm{~h}$ darkness photoperiod at $22^{\circ} \mathrm{C}$ with $70 \%$ humidity. Freshly collected ppJ 2 $M$. incognita were counted, and 1,000 nematodes were inoculated in each plant. The first nematode bioassay was conducted with $\mathrm{T} 1 \mathrm{plants}$ using five independent transgenic lines expressing HSP90 dsRNA and five lines expressing $I C L$ dsRNA. From each line, five individual plants were analyzed. The plants were harvested at $45 \mathrm{DAI}$, and the roots were individually washed, and their fresh weight was determined, after which they were triturated using a blender for $2 \mathrm{~min}$ in $0.5 \% \mathrm{NaClO}$. Using the resulting material, eggs were collected with a $32-\mu \mathrm{m}$ sieve and sampled three times for counting in a Peter's chamber. For each target gene, the two best T1 lines as determined from the first bioassay were multiplied to generate four T2 lines for each T1 line, which were subsequently used in the second bioassay. The second bioassay was performed on eight plants from each T2 line as previously described. The egg samples obtained in the second bioassay were then analyzed by qPCR to confirm the gene knock-down. The collected eggs were pooled and were used for RNA extraction using the RNeasy Kit (Qiagen). For qPCR, 500 ng of total RNA was reverse transcribed using SuperScript III (Life Technologies) following the manufacturer's instructions. Unfortunately, due to the small number of eggs collected from the plants expressing ICL dsRNA, the extracted RNA did not result in sufficient quantity and good quality to perform qPCR.

Morphological analysis of $M$. incognita-induced galls on tobacco roots expressing dsRNA. The seeds of transgenic tobacco plants (T1) expressing dsRNA of HSP9O (lines 1 and 5) and ICL (lines 1 and 3) were sterilized, germinated, and selected in MS media supplemented with kanamycin $(300 \mu \mathrm{g} / \mathrm{ml})$ and wild-type seeds were germinated in MS media. After germination, 20 plants of each treatment were transferred to $300-\mathrm{ml}$ pots containing sterile soil and were maintained in a growth chamber with a $16 \mathrm{~h}$ light $/ 8 \mathrm{~h}$ darkness photoperiod at $22^{\circ} \mathrm{C}$. The plant roots were inoculated with $1,000 \mathrm{ppJ} 2$ $M$. incognita per plant. The galls of transgenic and wild-type tobacco plants were collected at 14 and 28 DAI. The samples were fixed for 1 week using $2 \%$ glutaraldehyde in $50 \mathrm{mM}$ PIPES buffer, $\mathrm{pH} 6.9$, dehydrated using an ethanol dilution ( $\mathrm{vol} / \mathrm{vol})$ series $(10,30,50,70,90$, and $100 \%$ ), and then embedded in Technovit 7100 (Heraeus-Kulzer, Germany) as recommended by the manufacturer. The embedded roots and gall tissues were sectioned $(3 \mu \mathrm{m})$, stained in $0.05 \%$ toluidine blue, and mounted in Depex (Sigma, St. Louis, MO). Microscopic observations were performed using bright-field optics, and the images were collected using a digital camera (AxiocamHRc, Zeiss).

Data analysis. Number of eggs and galls per gram of roots were analyzed using Microsoft Excel to calculate means and standard deviation. Statistically significant differences were estimated by Student's $t$ test using GraphPad software. The statistical analysis of qPCR data were done using REST 2009 software, according to the iteration test.

\section{RESULTS}

M. incognita target gene selection. To avoid low efficiency of gene silencing due to nucleotide divergence, as a consequence of 
separately evolving populations, and to increase dbEST, we have generated an EST library of $M$. incognita $\mathrm{ppJ} 2$ from a Brazilian population.

The 2,378 ESTs deposited at dbEST were compared with the 63,838 previous $M$. incognita EST, resulting in 860 no hits (36\% of novelty), which is some improvement of database. Thus, $1,517 \mathrm{EST}$ had an identical or similar EST previously deposited, but only 130 had gene annotation. The sequence length of singlets and contigs ranged from $100 \mathrm{bp}$ to $2.55 \mathrm{~kb}$, with the highest number of sequences around $800 \mathrm{bp}$ (Supplementary Fig. 1). The 1,703 predicted cDNAs paired especially with nematode species (Supplementary Figs. 2 and 3), after BLASTx comparisons with the nonredundant (nr) protein database of NCBI, without $M$. incognita genome data (Supplementary Fig. 4). The EST distribution was 1\% for the genus Meloidogyne, 2\% for Heterodera and Globodera genera (Supplementary Table 2), $50 \%$ for other nematodes (especially C. elegans), $32 \%$ for any species outside the nematode phylum, and $14 \%$ for unknown sequences. The most abundant genes detected may be due to their high expression in ppJ2 (Supplementary Table 3). ESTs were also classified in gene ontology groups of molecular function (Supplementary Fig. 5) and biological process (Supplementary Fig. 6).

To avoid undesirable cross gene silencing in crop species, consumers, and nontarget species (e.g., free-living nematodes), the first criterion of choice for the candidate target genes was very low sequence identity with any gene from any species except plantparasitic nematodes or the absence of homologous genes in nontarget species. The second criterion was the high sequence identity with other plant-parasitic nematodes, to induce a wide-range resistance. Based on these criteria, the first candidate chosen was the HSP9O EST (accession number GU441459), which showed high sequence identity (e-value of e-109) only with phytoparasitic nematode genes and was represented by 5 reads. Previous studies with HSP90 have demonstrated its involvement in mechanisms that allow tolerance of several stress conditions such as heat, cold, freezing, and dehydration. In addition, an association of HSP90 with nematode long-living and survival mechanisms was observed in different nematode species within different ecological niches (see discussion section).

To target stress tolerance mechanisms, a second candidate gene was selected, which was the glyoxylate cycle-related ICL gene. Nematode embryogenesis, metabolism during the nonfeeding larval stages, and survival during starvation are presumably regulated by glyoxylate cycle. In addition, ICL is activated in developmentally arrested larvae, particularly during the dauer developmental program but is also involved in tolerance mechanisms to counteract freezing and dehydration stress. Thus, aiming to disrupt RKN parasitism, we chose $H S P 90$ and $I C L$ gene as targets for in planta RNAi strategy, due to their putative essential roles in $M$. incognita.

$H S P 90$ and $I C L$ transcript levels at different $M$. incognita life stages. To analyze the HSP9O and ICL expression levels in M. incognita, in silico analysis of the EST databank (dbEST http:// www.ncbi.nlm.nih.gov/dbEST/index.html) was performed using search tools to identify specific ESTs according to their gene annotations. The dbEST databank included 63,838 M. incognita ESTs (December 2013) of which 14,671 from eggs, 35,358 from $\mathrm{ppJ} 2$, 2,734 from mixed parasitic J2/J3/J4, and 4,427 from adult females. A search for HSP90 and ICL ESTs among the nonredundant protein sequences (NRdb-NCBI) of Nematoda (taxid: 6321) was performed using BLASTx with a cutoff of E-value $<\mathrm{e}-10$. Glyceraldehyde 3-phosphate dehydrogenase (GAPDH) was used as reference. The egg and ppJ 2 showed 30 and 31 HSP9O ESTs and 2 and 18 ICL ESTs, respectively. No ESTs were found for the parasitic stages most likely because the total number of ESTs was low and was representative for comparisons. During maturation from eggs/J1 to $\mathrm{ppJ} 2$ of $M$. incognita, the percentage of $H S P 90 \mathrm{EST}$ dropped to half, whereas the percentage of $I C L$ ESTs increased five times, although the HSP90 ESTs in the databank were always more abundant in the databank than ICL ESTs (Supplementary Fig. 9).
Quantitative PCR was performed to determine the temporal expression profiles of the HSP90 and ICL target genes at different nematode life phases. The transcript level was compared with the level in eggs. The HSP90 transcript levels showed a small degree of variation at the different life stages, with an eightfold increase in the parasitic J2/J3/J4 compared with the level in ppJ2 (Fig. 1A). In contrast, $I C L$ appeared to be strongly developmentally regulated. Compared with the level in eggs, the ICL transcript levels were 58fold higher in the $\mathrm{pp} \mathrm{J} 2$ phase, not detected in the parasitic $\mathrm{J} 2 / \mathrm{J} 3 / \mathrm{J} 4$, and fivefold higher in females (Fig. 1B).

To determine the localization of the $H S P 90$ and ICL transcripts in ppJ2 nematodes, whole mount in situ hybridization was performed. A strong HSP90 hybridization signal was observed in the digestive system (Fig. 2A). The ICL transcripts were strongly expressed in intestinal cells and at the tail end where lipid storage is observed (Fig. 2C). No signal was observed in the control samples hybridized using the sense probes for both genes (Fig. 2B and D).

Nematode reproduction, gall formation, and feeding site morphology on GM tobacco plants expressing HSP90 or ICL dsRNA. To determine the level of resistance to the nematodes, we conducted two infection bioassays. In the first bioassay, five individual plants (T1) derived from five independent transgenic events were analyzed per target gene, and five wild-type tobacco plants were used as the control (Fig. 3). The eggs were collected at
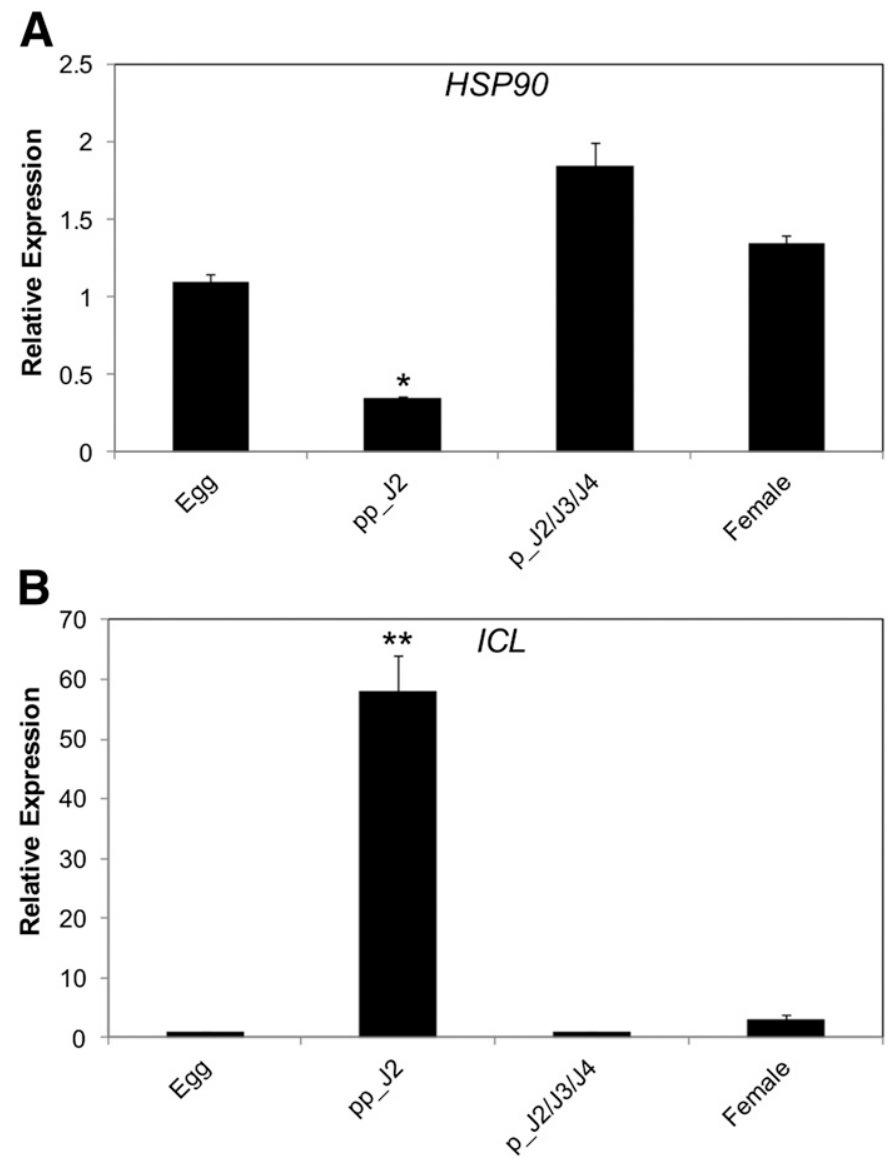

Fig. 1. Relative expression of heat-shock protein 90 (HSP90) and isocitrate lyase (ICL) transcripts during Meloidogyne incognita developmental stages. Quantitative real-time polymerase chain reaction was performed to determine transcript accumulation of $\mathbf{A}, H S P 90$ and $\mathbf{B}, I C L$. The amplifications were performed in triplicate using egg, $\mathrm{ppJ} 2, \mathrm{~J} 2 / \mathrm{J} 3 / \mathrm{J} 4$, and adult female cDNA with specific primers and SYBR Mix using the 7500ABI machine. The data were analyzed by Miner and qBase softwares. The transcript expression levels were normalized with GAPDH, $\beta$-tubulin, elongation factor, and $18 S$ rRNA as reference genes. The bars indicate mean values and standard deviation are presented as vertical lines. The asterisks indicate statistical difference $(* P \leq$ 0.05 ; ** $P \leq 0.01)$ according to the iteration test (REST 2009 software). 
45 DAI and were counted. Two HSP90 lines $(2,5)$ showed a significant $(P \leq 0.05)$ reduction compared with the wild type, corresponding to 18 and $28 \%$ fewer eggs per gram of root, respectively. The $H S P 90$ line 1 showed the highest significant $(P \leq 0.01)$ reduction of $37 \%$ (Fig. 3A). In parallel, five T1 plants of each five different lines expressing ICL dsRNA were tested. ICL lines 2, 4, and 6 showed significant $(P \leq 0.01)$ reduction of 53 to $58 \%$ in eggs per gram of root compared with wild-type plants (Fig. 3B). ICL lines 1 and 3 showed higher reduction $(P \leq 0.001)$, hitting $65 \%$.

Based on the results of this first bioassay, the two best $H S P 90$ and ICL T1 lines were propagated to generate four T2 subfamilies for each T1 line. A second bioassay was conducted using eight individual plants (T2) from each subfamily (Fig. 4). The HSP90 lines $1.1,1.3,5.1$, and 5.4 showed a significant $(P \leq 0.05)$ decrease of 29 to $46 \%$ in eggs per gram of root (Fig. 4A). The HSP 90 lines 1.2 and 5.2 showed a significant $(P \leq 0.01)$ reduction of 40 and $36 \%$, respectively. All ICL lines showed high significant difference $(P \leq$ 0.001 ) compared with the wild-type tobacco, hitting 52 to $77 \%$ reduction in egg per gram of root (Fig. 4B).

A third bioassay was performed to analyze number of galls formed at 14 and $28 \mathrm{DAI}$, using $10 \mathrm{~T} 1$ plants of the two best $H S P 90$ and ICL lines. HSP9O lines 1 and 5 showed significant $(P \leq 0.01)$ reduction of $50 \%$ in galls per gram of root compared with wild-type plants at 14 DAI (Fig. 5A). The ICL lines 1 and 3 at 14 and 28 DAI showed a similar number of galls per gram of root between them and compared with wild-type tobacco (Fig. 5B).

To characterize the morphology of feeding sites from HSP9O and ICL lines and compare them to those of the wild-type tobacco, we performed microscopic analysis of the galls collected at 14 and 28 DAI from the experiment described above. The morphological studies of feeding sites showed that giant cells did not differ in size or morphology from wild-type tobacco galls (Fig. 6), except for an apparent reduction of the size of the giant cells in the galls of the $H S P 90$ lines at 14 DAI.

To confirm $H S P 90$ or $I C L$ gene silencing and to investigate the potential hereditary effect of the silencing in the offspring, qPCR was performed using eggs collected from GM tobacco plants at 45 DAI during the second infection test, as described above. The total RNA was extracted from the first generation eggs of $M$. incognita that fed on plants expressing $H S P 90$ dsRNA, and these RNA samples were used for the qPCR analysis to evaluate the $H S P 90$ transcript level of each T2 line (Fig. 7). The HSP90 transcript levels of the eggs derived from animals that had fed on the HSP 90 dsRNA line were sevenfold lower than those of wild-type tobacco. This decrease represents a reduction of $85.7 \%$ compared with that of nematodes that fed on wild-type plants (Fig. 7). The persistence of ICL gene silencing could not be evaluated due to the small number of eggs produced, which resulted in poor RNA quantity and quality.

\section{DISCUSSION}

Here, we report the characterization of two stress-resistant and survival-related transcripts, $H S P 90$ and ICL, of M. incognita, and their evaluation as targets for gene silencing by the dsRNA delivery system in planta.

The EST library of a Brazilian population of $M$. incognita reported here showed HSP90 as highly expressed in $\mathrm{ppJ} 2$, in addition to its high sequence identity with nematode orthologs (Supplementary Table 3). HSP90 is an essential protein occurring in all eukaryotes with a multifunctional role and is related to chaperone signal transduction proteins such as kinases and growth factors (69) that are wellcharacterized in nematodes (25). Because HSP90 shows high sequence identity between nematodes, it has recently become a molecular marker for nematode identification and phylogenetic analysis $(32,82,83)$. Considering nematode HSP90 dendrograms, the following three groups were formed according to their life history: the first group consisted of free-living nematodes and parasitic nematodes with a free-living stage; the second group included obligatory parasitic nematodes; and the third group was comprised of plant-parasitic nematodes (38). The HSP90 sequence was used for RKN identification of M. floridensis (35), M. thailandica (34), M. hapla (36), and

\section{HSP9O}

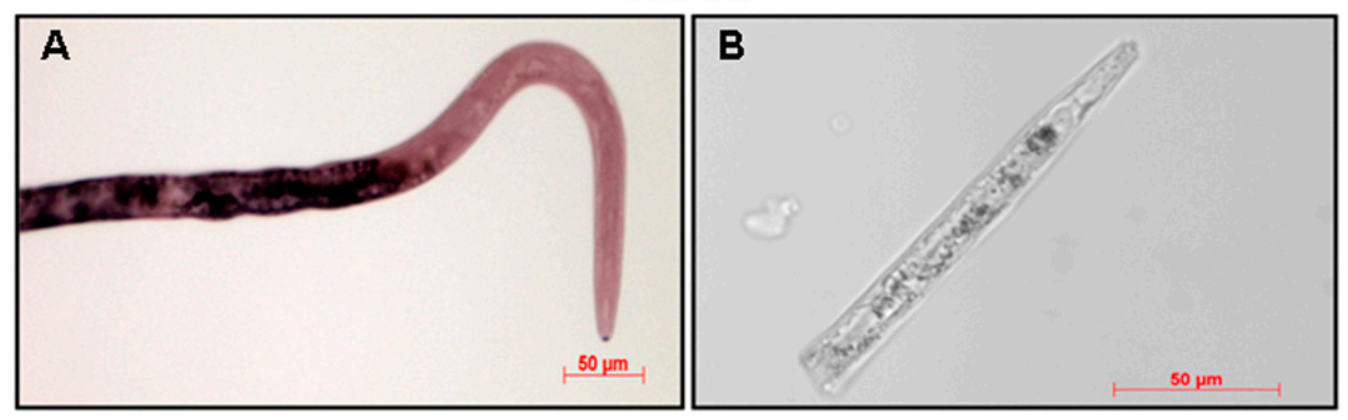

ICL

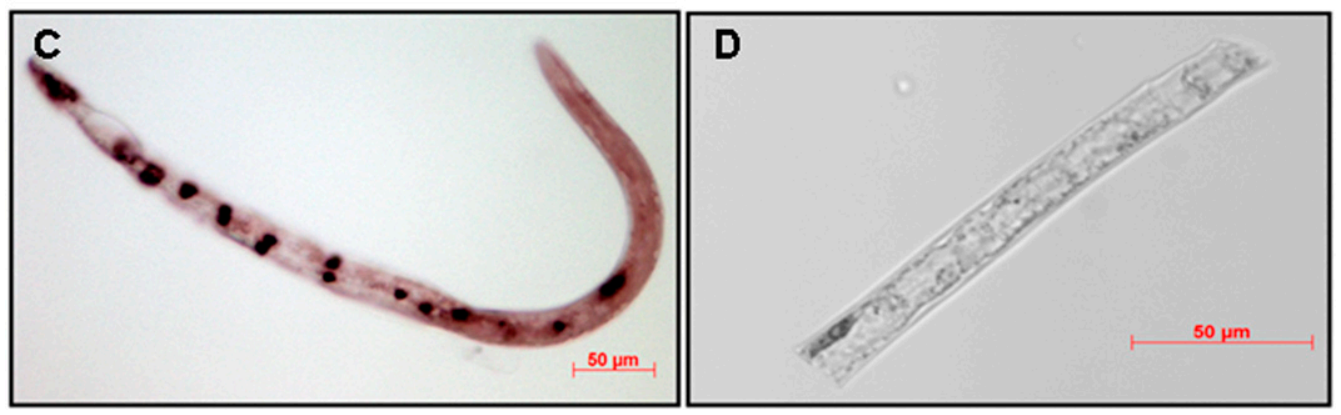

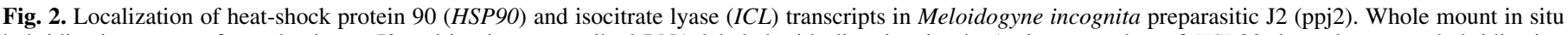

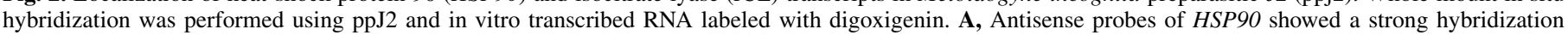

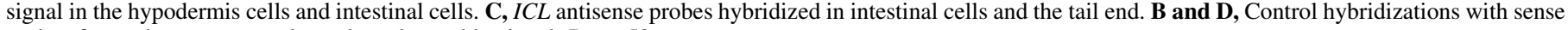
probes for each target gene showed no detectable signal. Bars, $50 \mu \mathrm{m}$. 
M. arenaria (81), resulting in phylogenetic tree similar to that one based on ribosomal genes (61). HSP90 as a molecular marker was also used in H. elachista (56). In that way, HSP90 gene was identified as a potential knock-down target, once it is highly conserved among plant-parasitic nematodes and could bring a wide range resistance.

The C. elegans dauer has 10- to 15-fold increased expression of $H S P 90$ (also named as DAF-21), suggesting an important role in stress-resistant mechanisms (73). Indeed, several nematode HSPs are induced in response to a variety of abiotic and biotic stressors (90). Despite, heat stress did not induce HSP90 in either Brugia or C. elegans $(26,86)$; another study reported increased HSP9O expression following heat shock in C. elegans (42). The Trichinella spiralis, T. nativa, and T. nelsoni nematodes do not change HSP9O levels in response to oxidative or cold stress (58). Dehydration stress in Belgica antarctica did not change $H S P 90$ expression $(71,74)$, but their developmental arrested larvae increased HSP9O expression (55). HSP90 expression was not up-regulated during desiccation and freeze stress in Plectus murrayi (2), and cold treatment did not activate this gene (4). In the RKN M. artiellia, exposure to low temperature $\left(5^{\circ} \mathrm{C}\right)$ increased $H S P 90$ expression in egg masses but not in ppJ2 (24). Overall, HSP90 expression is generally not induced by heat, cold, freeze, oxidative and dehydration stress, suggesting that $H S P 90$ is always constitutively expressed at high levels (3) without disrupting normal metabolism or the synthesis of other proteins (4).
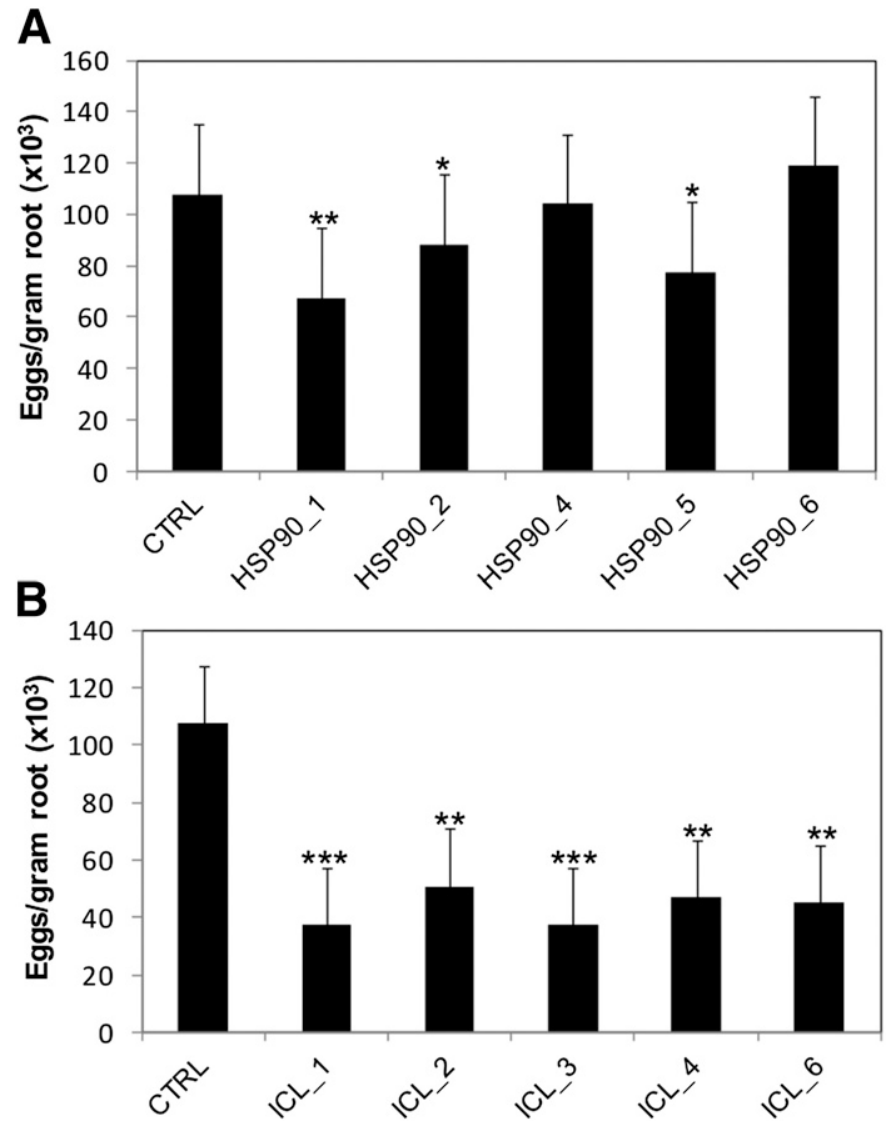

Fig. 3. The effects of $\mathrm{T} 1$ tobacco plants expressing heat-shock protein 90 (HSP90) and isocitrate lyase (ICL) double-stranded RNA (dsRNA) on Meloidogyne incognita reproduction. The first bioassay was performed with five T1 plants for each of the five different lines for each target gene to determine the egg number per gram of roots at 45 days after inoculation as shown as bars. A, The results of tobacco lines (lines 1, 2, 4, 5, and 6) expressing HSP90 dsRNA. B, The results of tobacco lines (lines 1, 2, 3, 4, and 6) expressing ICL dsRNA. Wild-type tobacco plants were used as experiment control (CRTL). Statistical significance was estimated by the Student's $t$ test ( $\left.{ }^{*} P \leq 0.05 ; * * P \leq 0.01 ; * * * P \leq 0.001\right)$.
We detected the lowest $H S P 90$ transcript abundance in $M$. incognita ppJ2, and an eightfold increase after aging to parasitic J2, J3, and J4 (Fig. 1A). Similarly, HSP90 expression in H. glycines was only upregulated in parasitic J2 (29). HSP90 in M. artiellia showed higher levels in young egg masses and J4 (24). Unexpectedly, both ppJ2 species, the most exposed phase to the environment adverse conditions, expressed the lowest HSP90 levels, while the highest HSP90 expression occurs in parasitic juveniles. These results suggest that the role of HSP90 in protecting plant-parasitic nematodes from plant defense mechanisms, such as oxidative stress, could represent worse stressing conditions than soil environment. Supporting this idea, when HSP90 was knocked down, we observed a delay in feeding site formation and a reduction in gall number of approximately $50 \%$ in tobacco lines expressing HSP9O dsRNA at 14 DAI (Figs. 5 and 6). The females grown on GM tobacco showed up to $46 \%$ reduction in eggs per gram of roots (Figs. 3 and 4). Despite the mean values of HSP90 descendent lines (1.1, $1.2,1.3$, and 1.4 group or 5.1, 5.2, 5.3 and 5.4 group) were similar to parental lines (HSP90_1 or HSP90_5). Some variation was observed between T2 family lines. Considering some transgene copies and/or different insertion sites, showing different transcription rates, gene dosage became complex. However, the observed variations could be just due to transgene segregation. Another explanation that could be further addressed is the putative DNA methylation driven by transcriptional gene silencing (48), altering dsRNA transcription and reflecting in a differential induced resistance to $M$. incognita.

A sevenfold decrease in HSP9O expression was observed in eggs obtained on GM plants (Fig. 7), which could be a consequence

A

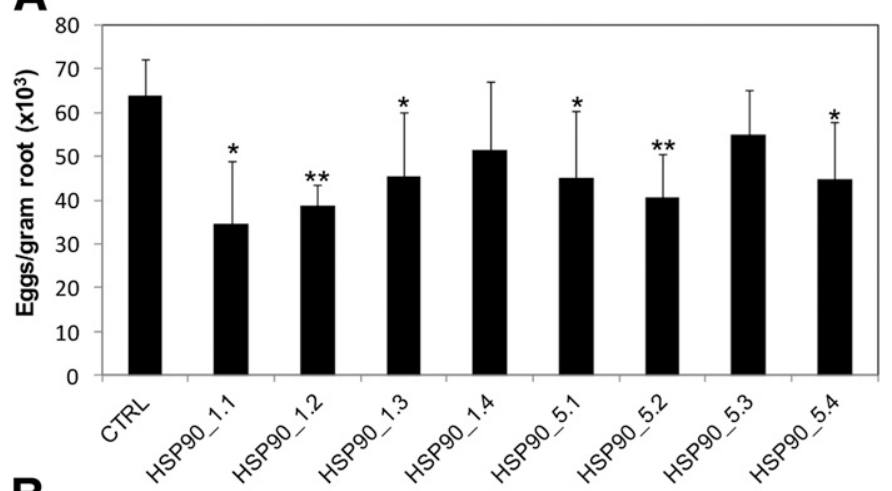

B

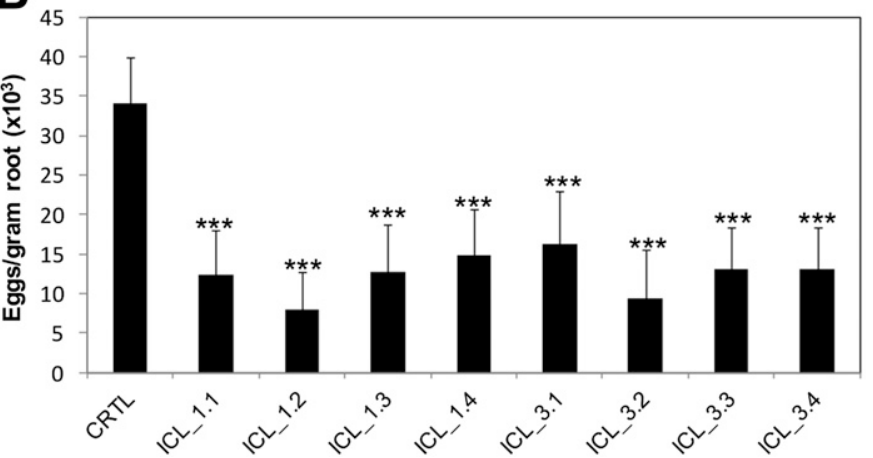

Fig. 4. The effects of $\mathrm{T} 2$ tobacco plants expressing heat-shock protein 90 (HSP90) and isocitrate lyase (ICL) double-stranded RNA (dsRNA) on Meloidogyne incognita reproduction. The second bioassay was performed with eight T2 plants for each of the four families multiplied from the two best lines of the first bioassay for each target gene. The egg number per gram of roots was determined at 45 days after inoculation, shown as bars. A, The results of tobacco family lines expressing $H S P 90$ dsRNA. B, The results of tobacco lines expressing ICL dsRNA. Wild-type tobacco plants were used as experiment control (CRTL). Statistical significance was estimated by the Student's $t$ test $\left({ }^{*} P \leq 0.05 ; * * P \leq 0.01 ; * * * P \leq 0.001\right)$. 
of transcriptional gene silencing mediated by dsRNA, as a result of DNA methylation of $M$. incognita $H S P 90$ promoter, a heritable gene silencing. Similarly, daf-21 silencing in C. elegans resulted in sterility, beyond gut blocking and embryonic lethality $(21,33)$. Taking together, our data and previous studies suggest that HSP90 may play a role in plant defense evasion as well as nematode reproduction.

Targeting $M$. incognita stress tolerance mechanisms, the glyoxylate cycle pathway called our attention. Usually not present in animals, this pathway is a bypass of the citric acid cycle, which depends on ICL and malate synthase (MS) enzymes (17,66,75-77). Nematodes employ the glyoxylate cycle to generate carbohydrates from the beta-oxidation of fatty acids (12). Curiously, only one bifunctional glyoxylate cycle protein that contains both ICL and MS domains was described in C. elegans (53). After this finding, an ortholog was also identified in the parasitic nematode Strongyloides stercoralis (80). This bifunctional ICL-MS gene may have first evolved by the fusion of the respective genes in a yet unknown bacterial operon, followed by a lateral gene transfer to the nematode common ancestor, which is supported by genomic studies of several nematodes that possess a bifunctional, fused ICL-MS gene (47). EST databank presents $I C L$ transcripts in several nematodes, including plant-parasitic G. rostochiensis, $H$. glycines, $M$. hapla, and $M$. javanica, and MS transcripts in G. rostochiensis, H. glycines, H. schachtii, M. arenaria, M. incognita, and M. javanica (47).

During the embryogenesis of Ascaris, lipids within eggs are converted to carbohydrates (65) and this carbohydrate synthesis during early development was correlated with decreasing levels of lipids in Ascaris lumbricoides and in C. elegans $(11,45)$. Thus, high activity of the glyoxylate cycle enzyme is necessary during nematode embryogenesis (14). The highest levels of glyoxylate cycle enzyme activity occur just prior to the hatching of C. elegans and A. lumbricoides

A

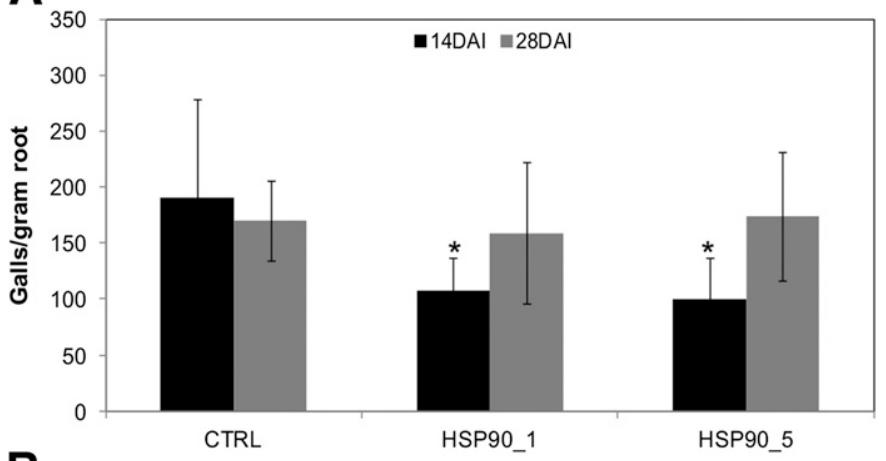

B

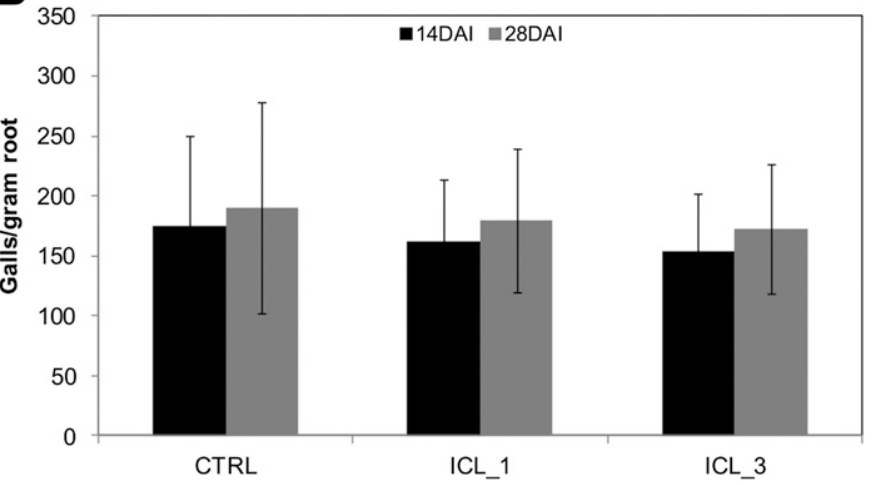

Fig. 5. Infection tests on tobacco plants expressing heat-shock protein 90 (HSP90) and isocitrate lyase (ICL) dsRNA. Gall counting was performed with $10 \mathrm{~T} 1$ plants at 14 and 28 days after inoculation (DAI). A, The tobacco lines 1 and 5 expressing $H S P 90$ dsRNA and B, tobacco lines 1 and 3 expressing ICL dsRNA. Wild-type plants were used as controls (CTRL). Statistical significance was estimated through the Student's $t$ test $(* P \leq 0.05)$. eggs (45) and for unhatched larvae of $N$. battus (8) and G. rostochiensis (67). Indeed, Haemonchus contortus increased ICL activity in the final larval stages (15).

In addition to embryogenesis, nematodes appear to use the glyoxylate cycle during starvation or during the nonfeeding phases (89). Up to $35 \%$ of the C. elegans body is composed of lipids, which

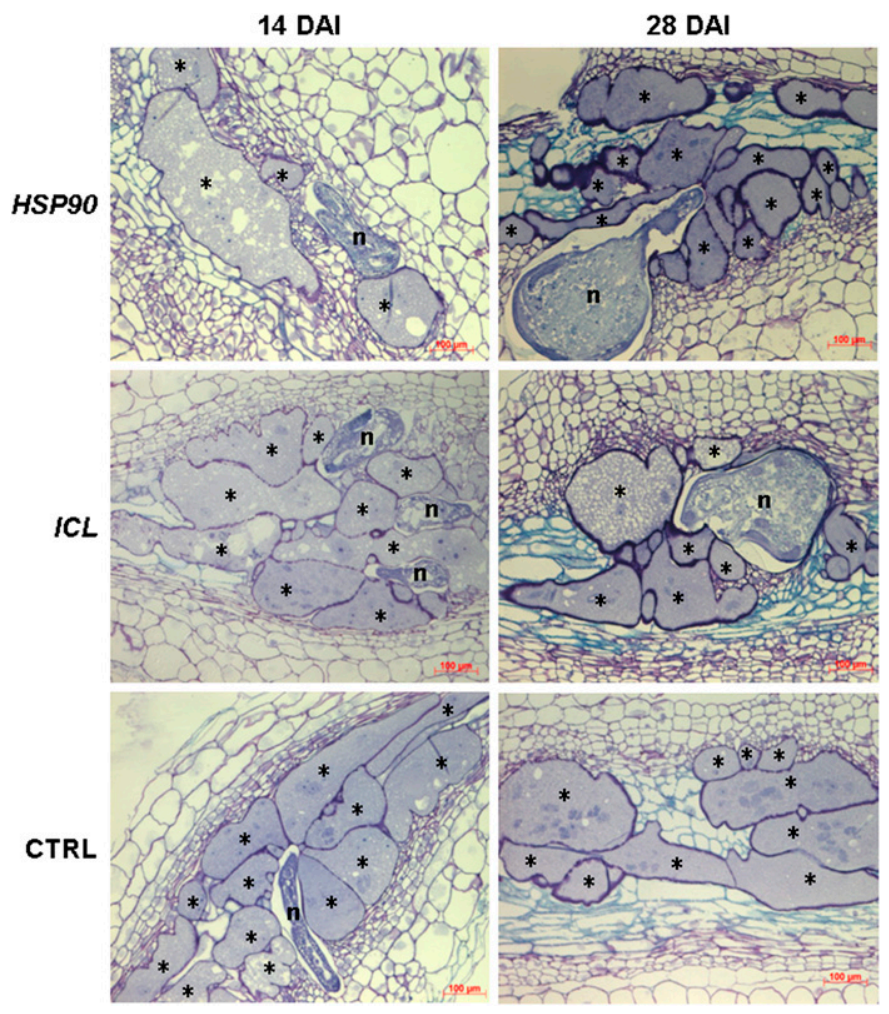

Fig. 6. Morphological analysis of feeding sites at 14 and 28 days after inoculation (DAI) on tobacco plants expressing heat-shock protein 90 (HSP90) and isocitrate lyase (ICL) dsRNA. Bright-field images of toluidine bluestaining of gall sections. Galls were collected from the same plants described in Figure 5. n, nematode; *, giant cell; bars, $100 \mu \mathrm{m}$.

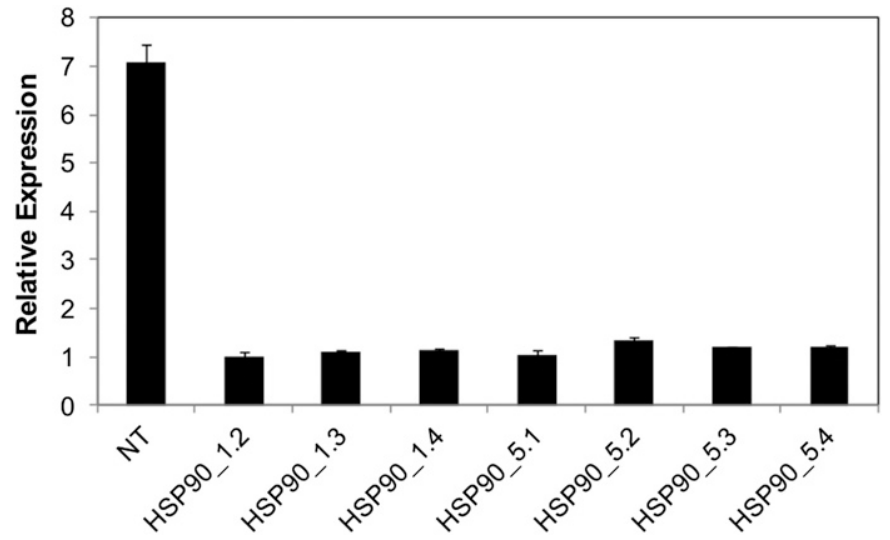

Fig. 7. Relative expression of heat-shock protein 90 (HSP90) transcripts of Meloidogyne incognita eggs raised on genetically modified tobacco lines. Quantitative real-time polymerase chain reaction was performed to determine transcript accumulation of HSP9O in nematode eggs obtained from T2 plants expressing HSP90 double-stranded RNA at 45 days after inoculation. Amplifications were conducted in triplicate using egg cDNA with specific primers and SYBR Mix in the 7500ABI machine. The data were analyzed using Miner and $\mathrm{qBase}$ softwares. The transcript expression level was normalized with GAPDH, $\beta$-tubulin, elongation factor, and $18 S$ rRNA as reference genes. The bars indicate mean values, and the standard errors are presented as vertical lines. NT, eggs obtained from nematodes feeding on nontransgenic wild-type plants used as a negative control. HSP90_1.2 to HSP90_5.4, eggs obtained from nematodes feeding on transgenic plants. 
is its major energy reserve $(20,49)$. Caenorhabditis spp. rapidly metabolize glycogen when starved and the dauer larvae rely on their lipid reserves for their longevity (62), suggesting that this pathway also occurs in post embryonic stages $(19,45)$. Interestingly, Liu et al. (54) reported that glyoxylate cycle mRNA and protein peaked in C. elegans early larvae which were never fed, declining with development stage or when nematode resume to feed.

Evidence suggests that trehalose resulting from the lipid to carbohydrate conversion may protect free-living stages from freezing and desiccating (8). Glyoxylate cycle activation was observed during anhydrobiosis in Aphelenchus avenae (57) and in P. murrayi (4). Desiccation and freezing stress in Antarctic nematodes induced the transcription of glyoxylate cycle genes (3), and MS expression is up-regulated upon desiccation and freezing stress in $P$. murrayi.

In silico analysis of dbEST showed a fivefold ICL increase when M. incognita $\mathrm{ppJ} 2$ hatched. As well, qPCR analysis revealed a 58 times higher level of the ICL transcript in ppJ 2 compared with eggs or during parasitic stages (Fig. 1B). Meloidogyne $\mathrm{ppJ} 2$ appear to use the glyoxylate cycle for energy and carbon backbone production from stored lipids during starvation or nonfeeding stages (72), while searching for a host (63), in addition to its putative role against desiccation or freezing stress. After parasitism establishment and feeding on giant cell contents, during the parasitic phases, the energetic metabolism is changed, decreasing ICL expression (60).

The lipid bodies of Ascaris suum larvae were localized in the posterior region, where glycogen levels increase and high glyoxylate cycle activity occurs (78). Like C. elegans dauers, RKN ppJ2 use this metabolic pathway (60) and exhibit numerous lipid storage vesicles in intestine and tail end that permit long-term survival in the soil. The ICL transcripts were successfully localized at tail ends and intestinal neighboring regions of $M$. incognita $\mathrm{ppJ} 2$ (Fig. 2C).

Tobacco plants expressing ICL dsRNA did not affect gall formation or feeding site structure induced by M. incognita (Figs. 5 and 6), a finding supported by its low transcription during parasitic stages (Fig. 1B), because of the activation of the citric acid cycle and inhibition of glyoxylate cycle when nematodes are feeding on roots. However, ICL knocking-down showed a reduction in the egg number per gram of root that ranged from 52 to $77 \%$ (Figs. 3 and 4). Similar results were observed between T1 ICL lines 1 and 3 and their T2 family lines obtained by self-pollination, with a mean value similar to parental. A short variation was observed between ICL descendant plants, which suggested a transgene copies segregating. Our data indicate that $I C L$ may play no direct role in parasitism, but $I C L$ has an essential function in nematode reproduction.

The essential, stress-related M. incognita HSP 90 and ICL genes have been characterized, and their potential to control phytonematodes was evaluated. Plants expressing ICL dsRNA represent a promising biotechnological tool for reducing $M$. incognita populations. Further studies will be necessary to determine the range of plant-parasitic nematodes that could be affected and to better characterize the effect of silencing these genes on nematode embryogenesis, stress-tolerance, starvation, and survival.

\section{ACKNOWLEDGMENTS}

This work was supported by grants from the Brazilian Agricultural Research Corporation (Embrapa), the National Council for Science and Technology (CNPq), the Brazilian Federal Agency for Support and Evaluation of Graduate Education (CAPES), and CAPES/COFECUB. We thank M. Magliano for contribution in whole mount ISH, N. Marteu for the production of biological material, and P. Viera for fruitful discussion.

\section{LITERATURE CITED}

1. Abad, P., Gouzy, J., Aury, J. M., Castagnone-Sereno, P., Danchin, E. G., Deleury, E., Perfus-Barbeoch, L., Anthouard, V., Artiguenave, F., Blok, V. C., Caillaud, M. C., Coutinho, P. M., Dasilva, C., De Luca, F., Deau, F., Esquibet, M., Flutre, T., Goldstone, J. V., Hamamouch, N., Hewezi, T., Jaillon, O., Jubin, C., Leonetti, P., Magliano, M., Maier, T. R., Markov,
G. V., McVeigh, P., Pesole, G., Poulain, J., Robinson-Rechavi, M., Sallet, E., Segurens, B., Steinbach, D., Tytgat, T., Ugarte, E., van Ghelder, C., Veronico, P., Baum, T. J., Blaxter, M., Bleve-Zacheo, T., Davis, E. L., Ewbank, J. J., Favery, B., Grenier, E., Henrissat, B., Jones, J. T., Laudet, V., Maule, A. G., Quesneville, H., Rosso, M. N., Schiex, T., Smant, G., Weissenbach, J., and Wincker, P. 2008. Genome sequence of the metazoan plant-parasitic nematode Meloidogyne incognita. Nat. Biotechnol. 26: 909-915.

2. Adhikari, B., Wall, D., and Adams, B. 2009. Desiccation survival in an Antarctic nematode: Molecular analysis using expressed sequenced tags. BMC Genomics 10:69.

3. Adhikari, B. N., and Adams, B. J. 2011. Molecular analyses of desiccation survival in Antarctic nematodes. Pages 205-232 in: Molecular and physiological basis of nematode survival. R. N. Perry and D. A. Wharton, eds. Plant Pathology and Microbiology Department, Rothamsted Research, Harpenden, Hertfordshire, UK.

4. Adhikari, B. N., Wall, D. H., and Adams, B. J. 2010. Effect of slow desiccation and freezing on gene transcription and stress survival of an Antarctic nematode. J. Exp. Biol. 213:1803-1812.

5. Alkharouf, N. W., Klink, V. P., and Matthews, B. F. 2007. Identification of Heterodera glycines (soybean cyst nematode [SCN]) cDNA sequences with high identity to those of Caenorhabditis elegans having lethal mutant or RNAi phenotypes. Exp. Parasitol. 115:247-258.

6. Altschul, S. F., Madden, T. L., Schaffer, A. A., Zhang, J., Zhang, Z., Miller, W., and Lipman, D. J. 1997. Gapped BLAST and PSI-BLAST: A new generation of protein data base search programs. Nucleic Acids Res. 25:3389-3402.

7. Antonino Souza Junior, J. D., Coelho, R. R., Lourenco, I. R., Fragoso, R. R., Viana, A. A. B., Macedo, L. L. P., Silva, M. C. M., Carneiro, R. M. G., Engler, G., Almeida-Engler, J., and Grossi-de-Sa, M. F. 2013. Knocking-down Meloidogyne incognita proteases by plant-delivered dsRNA has negative pleiotropic effect on nematode vigor. PLoS ONE 8:e85364.

8. Ash, C. P. J., and Atkinson, H. J. 1983. Evidence for a temperaturedependent conversion of lipid reserves to carbohydrate in quiescent eggs of the nematode Nematodirus battus. Comp. Biochem. Physiol. Part B Comp. Biochem. 76:603-610.

9. Bakhetia, M., Charlton, W., Atkinson, H. J., and McPherson, M. J. 2005. RNA interference of dual oxidase in the plant nematode Meloidogyne incognita. Mol. Plant-Microbe Interact. 18:1099-1106.

10. Bakhetia, M., Charlton, W. L., Urwin, P. E., McPherson, M. J., and Atkinson, H. J. 2005. RNA interference and plant parasitic nematodes. Trends Plant Sci. 10:362-367.

11. Barrett, J., Ward, C. W., and Fairbairn, D. 1970. The glyoxylate cycle and the conversion of triglycerides to carbohydrates in developing eggs of Ascaris lumbricoides. Comp. Biochem. Physiol. 35:577-586.

12. Barrett, J., and Wright, D. J. 1998. Intermediary metabolism. Pages 331-353 in: The Physiology and Biochemistry of Free-Living and PlantParasitic Nematodes. R. N. Perry and D. J. Wright, eds. CABI Publishing, Oxford.

13. Bird, D. M. K. I. 2003. Are roots special? Nematodes have their say. Physiol. Mol. Plant Pathol. 62:115-123.

14. Braeckman, B. P., Houthoofd, K., and Vanfleteren, J. R. 2005. Intermediary metabolism. In: WormBook: The Online Review of C. elegans Biology. WormBook, Pasadena, CA.

15. Carrington, M. J., Jasmer, D. P., and McFadden, B. A. 1987. Activities of isocitrate lyase and malate synthase during the development of free-living stages of Haemonchus contortus (Nematoda). Proc. Helminthological Soc. Wash. 54:277-279.

16. Chen, Q., Rehman, S., Smant, G., and Jones, J. T. 2005. Functional analysis of pathogenicity proteins of the potato cyst nematode Globodera rostochiensis using RNAi. Mol. Plant-Microbe Interact. 18:621-625.

17. Colonna, W. J., and McFadden, B. A. 1975. Isocitrate lyase from parasitic and free-living nematodes. Arch. Biochem. Biophys. 170:608-619.

18. Conesa, A., Götz, S., Garcia-Gomez, J. M., Terol, J., Talon, M., and Robles, M. 2005. Blast2GO: A universal tool for annotation, visualization and analysis in functional genomics research. Bioinformatics 21:3674-3676.

19. Cooper, A. F., and Van Gundy, S. D. 1970. Metabolism of glycogen and neutral lipids by Aphelenchus avenae and Caenorhabditis sp. in aerobic, microaerobic and anaerobic environments. J. Nematol. 2:305-315.

20. Cooper, A. F., and Van Gundy, S. D. 1971. Ethanol production and utilization by Aphelenchus avenae and Caenorhabditis sp. J. Nematol. 3:205-214.

21. Dalley, B. K., and Golomb, M. 1992. Gene expression in the Caenorhabditis elegans dauer larva: Developmental regulation of Hsp90 and other genes. Dev. Biol. 151:80-90.

22. de Almeida Engler, J., De Vleesschauwer, V., Burssens, S., Celenza, J. L., Jr., Inze, D., Van Montagu, M., Engler, G., and Gheysen, G. 1999. Molecular markers and cell cycle inhibitors show the importance of cell cycle progression in nematode-induced galls and syncytia. Plant Cell 11:793-808. 
23. de Boer, J. M., Yan, Y., Smant, G., Davis, E. L., and Baum, T. J. 1998. Insitu hybridization to messenger RNA in Heterodera glycines. J. Nematol. 30:309-312.

24. De Luca, F., Di Vito, M., Fanelli, E., Reyes, A., Greco, N., and De Giorgi, C. 2009. Characterization of the heat shock protein 90 gene in the plant parasitic nematode Meloidogyne artiellia and its expression as related to different developmental stages and temperature. Gene 440:16-22.

25. Devaney, E. 2011. Thermobiotic survival. Pages 233-255 in: Molecular and Physiological Basis of Nematode Survival. R. N. Perry and D. A. Wharton, eds. Plant Pathology and Microbiology Department, Rothamsted Research, Harpenden, Hertfordshire, UK.

26. Devaney, E., O'Neill, K., Harnett, W., Whitesell, L., and Kinnaird, J. H. 2005. Hsp90 is essential in the filarial nematode Brugia pahangi. Int. J. Parasitol. 35:627-636.

27. Dinh, P. T. Y., Brown, C. R., and Elling, A. A. 2014. RNA interference of effector gene Mc16D10L confers resistance against Meloidogyne chitwoodi in Arabidopsis and potato. Phytopathology 104:1098-1106.

28. Dinh, P. T. Y., Zhang, L., Brown, C. R., and Elling, A. A. 2014. Plantmediated RNA interference of effector gene Mc16D10L confers resistance against Meloidogyne chitwoodi in diverse genetic backgrounds of potato and reduces pathogenicity of nematode offspring. Nematology 16:669-682.

29. Elling, A. A., Mitreva, M., Recknor, J., Gai, X., Martin, J., Maier, T. R., McDermott, J. P., Hewezi, T., Mc, K. B. D., Davis, E. L., Hussey, R. S., Nettleton, D., McCarter, J. P., and Baum, T. J. 2007. Divergent evolution of arrested development in the dauer stage of Caenorhabditis elegans and the infective stage of Heterodera glycines. Genome Biol. 8:R211.

30. Fanelli, E., Di Vito, M., Jones, J. T., and De Giorgi, C. 2005. Analysis of chitin synthase function in a plant parasitic nematode, Meloidogyne artiellia, using RNAi. Gene 349:87-95.

31. Fernald, S. 2005. Comprehensive algorithm for quantitative real-time polymerase chain reaction. J. Comput. Biol. 12:1047-1064.

32. Floyd, R., Abebe, E., Papert, A., and Blaxter, M. 2002. Molecular barcodes for soil nematode identification. Mol. Ecol. 11:839-850.

33. Gillan, V., Maitland, K., McCormack, G., Him, N. A., and Devaney, E. 2009. Functional genomics of hsp-90 in parasitic and free-living nematodes. Int. J. Parasitol. 39:1071-1081.

34. Handoo, Z. A., Nyczepir, A. P., Esmenjaud, D., van der Beek, J. G., Castagnone-Sereno, P., Carta, L. K., Skantar, A. M., and Higgins, J. A. 2004. Morphological, molecular, and differential-host characterization of Meloidogyne floridensis n. sp. (Nematoda: Meloidogynidae), a root-knot nematode parasitizing peach in Florida. J. Nematol. 36:20-35.

35. Handoo, Z. A., Skantar, A. M., Carta, L. K., and Erbe, E. F. 2005. Morphological and molecular characterization of a new root-knot nematode, Meloidogyne thailandica $\mathrm{n}$. sp. (Nematoda: Meloidogynidae), parasitizing ginger (Zingiber sp.). J. Nematol. 37:343-353.

36. Handoo, Z. A., Skantar, A. M., Carta, L. K., and Schmitt, D. P. 2005. Morphological and molecular evaluation of a Meloidogyne hapla population damaging coffee (Coffea arabica) in Maui, Hawaii. J. Nematol. 37:136-145.

37. Hellemans, J., Mortier, G., De Paepe, A., Speleman, F., and Vandesompele, J. 2007. QBase relative quantification framework and software for management and automated analysis of real-time quantitative PCR data. Genome Biol. 8:R19.

38. Him, N. A., Gillan, V., Emes, R. D., Maitland, K., and Devaney, E. 2009. Hsp-90 and the biology of nematodes. BMC Evol. Biol. 9:254.

39. Homma, S., Horsch, A., Pouch, M. N., Petit, F., Briand, Y., and Schmid, H. P. 1994. Proteasomes (prosomes) inhibit the translation of tobacco mosaic virus RNA by preventing the formation of initiation complexes. Mol. Biol. Rep. 20:57-61.

40. Huang, G., Allen, R., Davis, E. L., Baum, T. J., and Hussey, R. S. 2006. Engineering broad root-knot resistance in transgenic plants by RNAi silencing of a conserved and essential root-knot nematode parasitism gene. Proc. Natl. Acad. Sci. USA 103:14302-14306.

41. Hussey, R. S., and Barker, A. A. 1973. Comparation methods of collecting inocula of Meloidogyne spp. including a new technique. Plant Dis. Rep. 57:1025-1028.

42. Inoue, T., Takamura, K., Yamae, H., Ise, N., Kawakami, M., Tabuse, Y., Miwa, J., and Yamaguchi, Y. 2003. Caenorhabditis elegans DAF-21 (HSP90) is characteristically and predominantly expressed in germline cells: Spatial and temporal analysis. Dev. Growth Differ. 45:369-376.

43. Karimi, M., Inze, D., and Depicker, A. 2002. GATEWAY vectors for Agrobacterium-mediated plant transformation. Trends Plant Sci. 7:193-195.

44. Katoch, R., and Thakur, N. 2013. RNA interference: A promising technique for the improvement of traditional crops. Int. J. Food Sci. Nutr. 64: 248-259.

45. Khan, F. R., and McFadden, B. A. 1982. Caenorhabditis elegans: Decay of isocitrate lyase during larval development. Exp. Parasitol. 54:47-54.

46. Kimber, M. J., McKinney, S., McMaster, S., Day, T. A., Fleming, C. C., and Maule, A. G. 2007. flp gene disruption in a parasitic nematode reveals motor dysfunction and unusual neuronal sensitivity to RNA interference. FASEB J. 21:1233-1243.

47. Kondrashov, F., Koonin, E., Morgunov, I., Finogenova, T., and Kondrashova, M. 2006. Evolution of glyoxylate cycle enzymes in Metazoa: Evidence of multiple horizontal transfer events and pseudogene formation. Biol. Direct 1:31.

48. Kyndt, T., Ji, H., Vanholme, B., and Gheysen, G. 2013. Transcriptional silencing of RNAi constructs against nematode genes in Arabidopsis. Nematology 15:519-528.

49. Lee, D. L., and Atkinson, H. J. 1976. Physiology of Nematodes. MacMillan, New York.

50. Li, J. R., Todd, T. C., Oakley, T. R., Lee, J., and Trick, H. N. 2010. Hostderived suppression of nematode reproductive and fitness genes decreases fecundity of Heterodera glycines Ichinohe. Planta 232:775-785.

51. Lilley, C. J., Davies, L. J., and Urwin, P. E. 2012. RNA interference in plant parasitic nematodes: A summary of the current status. Parasitology: 139:1-11.

52. Lilley, C. J., Goodchild, S. A., Atkinson, H. J., and Urwin, P. E. 2005. Cloning and characterisation of a Heterodera glycines amino peptidase cDNA. Int. J. Parasitol. 35:1577-1585.

53. Liu, F., Thatcher, J. D., Barral, J. M., and Epstein, H. F. 1995. Bifunctional glyoxylate cycle protein of Caenorhabditis elegans: A developmentally regulated protein of intestine and muscle. Dev. Biol. 169:399-414.

54. Liu, F., Thatcher, J. D., and Epstein, H. F. 1997. Induction of glyoxylate cycle expression in Caenorhabditis elegans: A fasting response throughout larval development. Biochemistry 36:255-260.

55. Lopez-Martinez, G., Benoit, J. B., Rinehart, J. P., Elnitsky, M. A., Lee, R. E., Jr., and Denlinger, D. L. 2009. Dehydration, rehydration, and overhydration alter patterns of gene expression in the Antarctic midge, Belgica antarctica. J. Comp. Physiol. B 179:481-491.

56. Luca, F., Vovlas, N., Lucarelli, G., Troccoli, A., Radicci, V., Fanelli, E., Cantalapiedra-Navarrete, C., Palomares-Rius, J., and Castillo, P. 2013. Heterodera elachista the Japanese cyst nematode parasitizing corn in Northern Italy: Integrative diagnosis and bionomics. Eur. J. Plant Pathol. 136:857-872.

57. Madin, K. A. C., Loomis, S. H., and Crowe, J. H. 1985. Anhydrobiosis in nematodes: Control of carbon flow through the glyoxylate cycle. J. Exp. Zool. 234:341-350.

58. Martinez, J., Perez-Serrano, J., Bernadina, W. E., and Rodriguez-Caabeiro, F. 2002. Oxidative and cold shock cause enhanced induction of a $50 \mathrm{kDa}$ stress protein in Trichinella spiralis. Parasitol. Res. 88:427-430.

59. Maule, A. G., McVeigh, P., Dalzell, J. J., Atkinson, L., Mousley, A., and Marks, N. J. 2011. An eye on RNAi in nematode parasites. Trends Parasitol. 27:505-513.

60. McCarter, J. P., Mitreva, M. D., Martin, J., Dante, M., Wylie, T., Rao, U., Pape, D., Bowers, Y., Theising, B., Murphy, C. V., Kloek, A. P., Chiapelli, B. J., Clifton, S. W., Bird, D. M., and Waterston, R. H. 2003. Analysis and functional classification of transcripts from the nematode Meloidogyne incognita. Genome Biol. 4:R26.

61. Nischwitz, C., Skantar, A., Handoo, Z. A., Hult, M. N., Schmitt, M. E., and McClure, M. A. 2013. Occurrence of Meloidogyne fallax in North America, and Molecular Characterization of M. fallax and M. minor from U.S. Golf Course Greens. Plant Dis. 97:1424-1430.

62. O'Riordan, V. B., and Burnell, A. M. 1990. Intermediary metabolism in the dauer larva of the nematode Caenorhabditis elegans-II. The glyoxylate cycle and fatty-acid oxidation. Comp. Biochem. Physiol. Part B Comp. Biochem. 95:25-130.

63. Opperman, C. H., Bird, D. M., Williamson, V. M., Rokhsar, D. S., Burke, M., Cohn, J., Cromer, J., Diener, S., Gajan, J., Graham, S., Houfek, T. D., Liu, Q., Mitros, T., Schaff, J., Schaffer, R., Scholl, E., Sosinski, B. R., Thomas, V. P., and Windham, E. 2008. Sequence and genetic map of Meloidogyne hapla: A compact nematode genome for plant parasitism. Proc. Natl. Acad. Sci. USA 105:14802-14807.

64. Papolu, P., Gantasala, N., Kamaraju, D., Banakar, P., and Sreevathsa, R. 2013. Utility of host delivered RNAi of two FMRF amide like peptides, flp-14 and flp-18, for the management of root knot nematode, Meloidogyne incognita. PLoS ONE 8:e80603.

65. Passey, R. F., and Fairbairn, D. 1957. The conversation of fat to carbohydrate during embryonation of Ascaris eggs. Can. J. Biochem. Physiol. 35:511-525.

66. Patel, T. R., and McFadden, B. A. 1977. Particulate isocitrate lyase and malate synthase in Caenorhabditis elegans. Arch. Biochem. Biophys. 183:24-30.

67. Perry, R. N. 1983. The effect of potato root diffusate on the desiccation survival of unhatched juveniles of Globodera rostochiensis. Rev. Nematologie 6:99-102.

68. Pfaffl, M. W. 2001. A new mathematical model for relative quantification in real-time RT-PCR. Nucleic Acids Res. 29:e45.

69. Picard, D. 2002. Heat-shock protein 90, a chaperone for folding and regulation. Cell. Mol. Life Sci. 59:1640-1648. 
70. Quentin, M., Abad, P., and Favery, B. 2013. Plant parasitic nematode effectors target host defense and nuclear functions to establish feeding cells. Front. Plant Sci. 4:53.

71. Ragsdale, E., Crum, J., Ellisman, M., and Baldwin, J. 2008. Threedimensional reconstruction of the stomatostylet and anterior epidermis in the nematode Aphelenchus avenae (Nematoda: Aphelenchidae) with implications for the evolution of plant parasitism. J. Morphol. 269:1181-1196.

72. Reversat, G. 1981. Consumption of food reserves by starved second stage juveniles of Meloidogyne javanica under conditions including osmobiosis. Nematologica 27:207-214.

73. Riddle, D. L., and Albert, P. S. 1997. Genetic and environmental regulation of dauer larva development. Pages 739-768 in: C. elegans II. D. L. Riddle, T. Blumenthal, B. J. Meyer, and J. R. Priess, eds. Cold Spring Harbor Laboratory, Cold Spring Harbor, NY.

74. Rinehart, J. P., Hayward, S. A., Elnitsky, M. A., Sandro, L. H., Lee, R. E., Jr., and Denlinger, D. L. 2006. Continuous up-regulation of heat shock proteins in larvae, but not adults, of a polar insect. Proc. Natl. Acad. Sci. USA 103:14223-14227.

75. Rothstein, M., and Mayoh, H. 1964. Glycine synthesis and isocitrate lyase in the nematode, Caenorhabditis briggsae. Biochem. Biophys. Res. Commun. 14:43-47.

76. Rothstein, M., and Mayoh, H. 1964. Nematode Biochemistry. Iv. On Isocitrate Lyase in Caenorhabditis briggsae. Arch. Biochem. Biophys. 108:134-142

77. Rothstein, M., and Mayoh, H. 1965. Nematode biochemistry. VII. Presence of isocitrate lyase in Panagrellus redivivus, Turbatrix aceti, and Rhabditis anomala. Comp. Biochem. Physiol. 16:361-365.

78. Rubin, H., and Trelease, R. N. 1975. Ultrastructure of developing Ascaris larvae undergoing lipid to carbohydrate interconversion. J. Parasitol. 61: 577-588.

79. Shingles, J., Lilley, C. J., Atkinson, H. J., and Urwin, P. E. 2007. Meloidogyne incognita: Molecular and biochemical characterisation of a cathepsin $\mathrm{L}$ cysteine proteinase and the effect on parasitism following RNAi. Exp. Parasitol. 115:114-120.

80. Siddiqui, A. A., Stanley, C. S., and Berk, S. L. 2000. Cloning and expression of isocitrate lyase from human round worm Strongyloides stercoralis. Parasite 7:233-236.

81. Skantar, A., Carta, L., and Handoo, Z. 2008. Molecular and morphological characterization of an unusual Meloidogyne arenaria population from traveler's tree, Ravenala madagascariensis. J. Nematol. 40:179-189.

82. Skantar, A. M., and Carta, L. K. 2000. Amplification of Hsp90 homologs from plant-parasitic nematodes using degenerate primers and ramped annealing PCR. Biotechniques 29:1182-1186.
83. Skantar, A. M., and Carta, L. K. 2004. Molecular characterization and phylogenetic evaluation of the hsp90 gene from selected nematodes. J. Nematol. 36:466-480.

84. Steeves R. M., Todd, T. C., Essig, J. S., and Trick, H. N. 2006. Transgenic soybeans expressing siRNAs specific to a major sperm protein gene suppress Heterodera glycines reproduction. Funct. Plant Biol. 33: 991-999.

85. Tatusov, R. L., Fedorova, N. D., Jackson, J. D., Jacobs, A. R., Kiryutin, B., Koonin, E. V., Krylov, D. M., Mazumder, R., Mekhedov, S. L., Nikolskaya, A. N., Rao, B. S., Smirnov, S., Sverdlov, A. V., Vasudevan, S., Wolf, Y. I., Yin, J. J., and Natale, D. A. 2003. The COG database: An updated version includes eukaryotes. BMC Bioinformatics 4:41.

86. Thompson, F. J., Cockroft, A. C., Wheatley, I., Britton, C., and Devaney, E. 2001. Heat shock and developmental expression of hsp83 in the filarial nematode Brugia pahangi. Eur. J. Biochem. 268:5808-5815.

87. Trudgill, D. L., and Blok, V. C. 2001. Apomictic, polyphagous root-knot nematodes: Exceptionally successful and damaging biotrophic root pathogens. Annu. Rev. Phytopathol. 39:53-77.

88. Vieira, P., Kyndt, T., Gheysen, G., and Engler, J. D. 2013. An insight into critical endocycle genes for plant-parasitic nematode feeding sites establishment. Plant Signal. Behav. 8:e24223.

89. Wadsworth, W. G., and Riddle, D. L. 1989. Developmental regulation of energy metabolism in Caenorhabditis elegans. Dev. Biol. 132:167-173.

90. Wharton, D. A. 2011. Cold tolerance. Pages 182-204 in: Molecular and Physiological Basis of Nematode Survival. R. N. Perry and D. A. Wharton, eds. Plant Pathology and Microbiology Department, Rothamsted Research, Harpenden, Hertfordshire, UK.

91. Xue, B. Y., Hamamouch, N., Li, C. Y., Huang, G. Z., Hussey, R. S., Baum, T. J., and Davis, E. L. 2013. The 8D05 parasitism gene of Meloidogyne incognita is required for successful infection of host roots. Phytopathology 103:175-181.

92. Yadav, B. C., Veluthambi, K., and Subramaniam, K. 2006. Hostgenerated double stranded RNA induces RNAi in plant-parasitic nematodes and protects the host from infection. Mol. Biochem. Parasitol. 148:219-222.

93. Yang, Y. Z., Jittayasothorn, Y., Chronis, D., Wang, X. H., Cousins, P., and Zhong, G. Y. 2013. Molecular characteristics and efficacy of 16D10 siRNAs in inhibiting root-knot nematode infection in transgenic grape hairy roots. PLoS ONE 8:e69463.

94. Youssef, R. M., Kim, K. H., Haroon, S. A., and Matthews, B. F. 2013. Post-transcriptional gene silencing of the gene encoding aldolase from soybean cyst nematode by transformed soybean roots. Exp. Parasitol. 134: 266-274. 